\title{
Heartland Virus in Humans and Ticks, Illinois, USA, 2018-2019
}

Holly C. Tuten, ${ }^{1}$ Kristen L. Burkhalter, ${ }^{1}$ Kylee R. Noel, Erica J. Hernandez, Seth Yates, Keith Wojnowski, John Hartleb, Samantha Debosik, April Holmes, Christopher M. Stone

In 2018, Heartland disease virus infected 2 persons in Illinois, USA. In 2019, ticks were collected at potential tick bite exposure locations and tested for Heartland and Bourbon viruses. A Heartland virus-positive pool of adult male Amblyomma americanum ticks was found at 2 locations, $439 \mathrm{~km}$ apart, suggesting widespread distribution in Illinois.

$\mathrm{H}$ eartland virus (HRTV), a phlebovirus in the order Bunyavirales, is an emerging zoonotic pathogen. In 2009, after 2 cases were identified in persons in Missouri, additional cases were subsequently reported from Kansas, Oklahoma, Arkansas, Missouri, Tennessee, Kentucky, Indiana, Georgia, and South Carolina. Disease onset was most often during April-September (1). HRTV symptoms can initially resemble those of ehrlichiosis (2) and include fatigue, fever, leukopenia, and thrombocytopenia (3). Human illness caused by HRTV infection often requires hospitalization and has resulted in death (1).

After 2 persons infected with HRTV in northwestern Missouri reported having noticed attached ticks before symptom onset (4), subsequent entomologic studies detected HRTV in nymphal Amblyomma americanum ticks. Laboratory studies confirmed the competence of $A$. americanum ticks for transmitting HRTV transstadially and horizontally (5). This body of evidence led to the implication of A. americanum ticks as the putative vector of $\operatorname{HRTV}(2,6)$. Serologic surveys of mammals and birds subsequently detected HRTV-specific neutralizing antibodies in a variety of

Author affiliations: University of Illinois at Urbana-Champaign, Champaign, Illinois, USA (H.C. Tuten, K.R. Noel, E.J. Hernandez,

S. Yates, C.M. Stone); Centers for Disease Control and

Prevention, Fort Collins, Colorado, USA (K.L. Burkhalter);

Kankakee County Health Department, Kankakee, Illinois, USA

(K. Wojnowski); US Fish \& Wildlife Service, Marion, Illinois, USA

(J. Hartleb); Illinois Department of Public Health, Springfield,

Illinois, USA (S. Debosik, A. Holmes)

DOI: https://doi.org/10.3201/eid2607.200110 mammals, including raccoons and white-tailed deer, suggesting that various medium- and large-sized mammals may serve as hosts $(3,7)$.

A. americanum ticks are vectors of public health concern because of their aggressive biting behavior, willingness to feed on humans, and abundance. Over the past century, their distribution range has expanded northward (8), and population establishment continues to increase because of climate change (9). Habitat suitability models have suggested that this species' fundamental niche should reach the center of Illinois (10) or eventually encompass the state entirely (9).

In July 2018, a Kankakee County, Illinois, resident (case-patient 1) reported having incurred multiple tick bites while camping on private residential property. The patient was hospitalized with fever, headache, myalgia, nausea, diarrhea, and a diffuse maculopapular rash. In September 2018, a Williamson County, Illinois, resident (case-patient 2) noticed tick bites while staying at a campground near home. The patient was hospitalized with fever, headache, myalgia, fatigue, decreased appetite, nausea, and diarrhea. The Centers for Disease Control and Prevention (CDC) confirmed that clinical samples from both patients were positive for HRTV. We subsequently performed entomologic investigations to determine tick density and HRTV prevalence among tick populations at the likely sites of exposure.

\section{The Study}

The suspected sites of human exposure were determined according to case-patient interviews conducted by local county health departments (Figure). Two of the 3 sites were in an area considered endemic for A. americanum ticks, and the other site was near the putative current northern distribution range limit for this tick vector. 
For case-patient 1 , the potential exposure site was an $\approx 40$-acre rural homestead in Kankakee County, which had an assemblage of barnyard animals, including chickens, goats, horses, and turkeys (site 1) and a small amount of forest surrounded by extensive cropland. For case-patient 2, in Williamson County, a potential exposure site consisted of 2 adjacent lakeshore campgrounds located within a heavily wooded wildlife refuge (site 2) and another was a suburban home with sparse tree cover (site 3 ). We observed deer at site 1 during collection visits on
June 21 and 25, 2019, and deer, coyotes, and racoons at site 2 during visits on July 11 and 12, 2019. A pet dog lived at the residence at site 3 , which we visited on July 11, 2019.

We collected ticks by dragging along $150-\mathrm{m}$ transects (sites 1 and 2) and with carbon dioxide traps consisting of a $1 \mathrm{~m}^{2}$ white cloth laid on the ground with $0.5 \mathrm{~kg}$ of dry ice left in the center to sublimate for 2 hours before returning to collect ticks (sites 1-3). We collected live ticks into $14-\mathrm{mL}$ plastic centrifuge tubes (TPP, https://www.tpp.ch) that had been
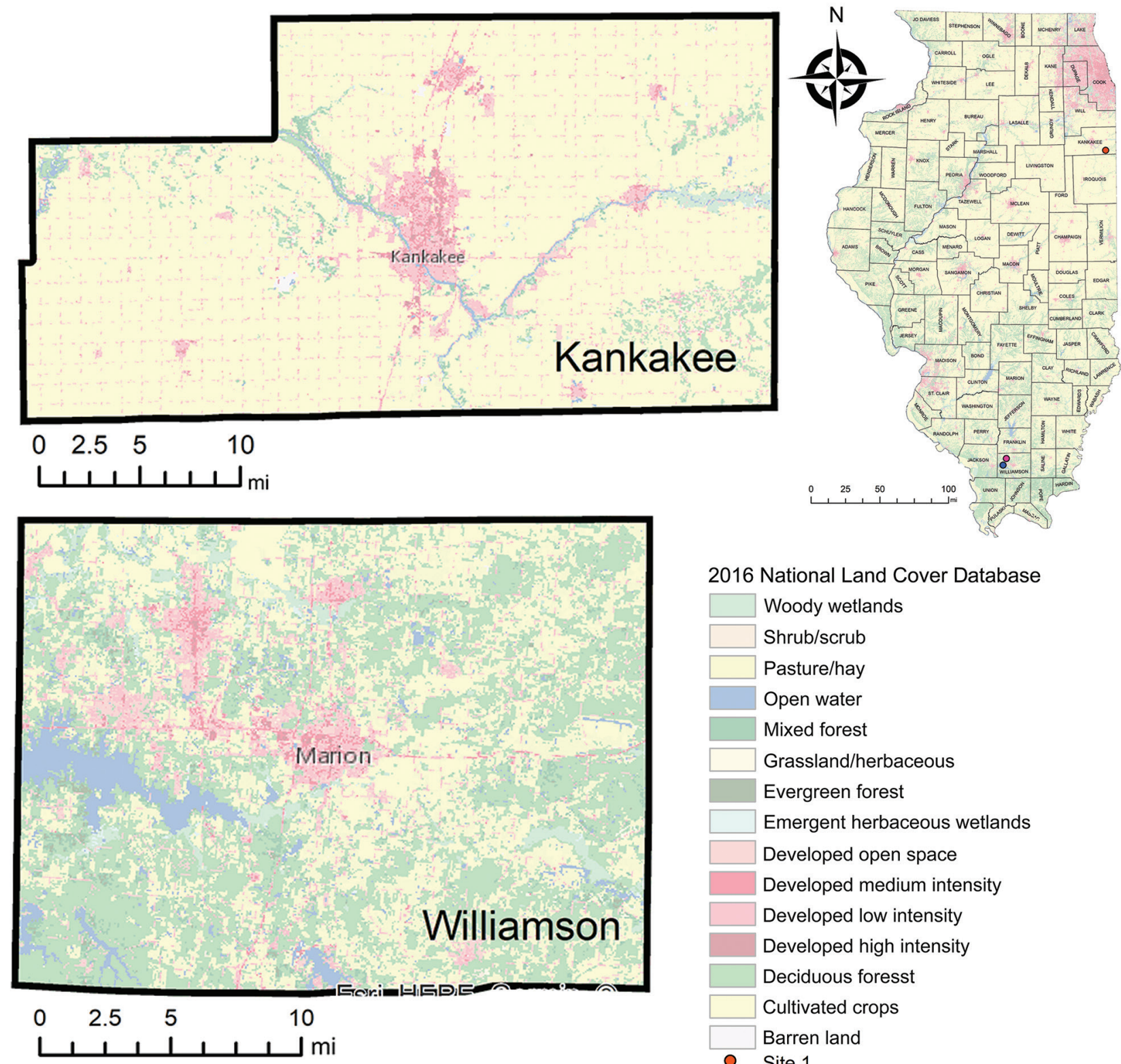

2016 National Land Cover Database

\begin{tabular}{|l|l|}
\hline & Woody wetlands \\
\hline & Shrub/scrub \\
\hline & Pasture/hay \\
\hline & Open water \\
\hline & Gixed forest \\
\hline & Evergreen forest \\
\hline & Emergent herbaceous wetlands \\
\hline & Developed open space \\
\hline & Developed medium intensity \\
\hline & Developed low intensity \\
\hline & Developed high intensity \\
\hline & Deciduous foresst \\
\hline & Cultivated crops \\
\hline & Barren land \\
\hline $0 \quad$ Site 1 \\
\hline$\quad$ Site 2 \\
\hline$\quad$ Site 3
\end{tabular}

Figure. Tick collection sites associated with 2 cases of Heartland virus infection in humans, Kankakee and Williamson Counties, Illinois, USA, 2019. Locations of the counties are indicated by red dots on the Illinois map. 
modified by applying carpet tape between the lid and tube mouth. We added ticks through a tape-covered hole punched in the center of the paper-backed side of the tape; the sticky side of the tape facing the tube interior immobilized the ticks before they could exit, enabling their secure transport while alive (Video, https:/ / wwwnc.cdc.gov / EID/article/26/7/200110-V1.htm). Ticks were either kept alive (site 1) or killed in the field at the end of the day and kept on dry ice (sites 2 and 3) during transport to the Illinois Natural History Survey Medical Entomology Laboratory (Champaign, IL, USA), where they were identified and sorted by species, life stage, and sex $(11,12)$ on a chill table and maintained at $-80^{\circ} \mathrm{C}$. Ticks were then shipped on dry ice to the CDC Arboviral Diseases Branch (Fort Collins, CO, USA) for Heartland and Bourbon virus testing, where tick pool homogenization, RNA extraction, and virus screening were performed by real-time PCR as previously described $(2,13)$. The prevalence of virus infection from pooled samples was calculated by using PooledInfRate, which implements a bias-corrected maximum-likelihood estimation method (14).
A total of 70 pools of adult ticks and 23 pools of nymphs were tested (Table 1). The median pool size for adult ticks was 10 (range 1-10) and for nymphs was 30 (range 3-33). A single pool of male A. americanum ticks from each county was positive for HRTV (cycle threshold values of 21.7 for site 1 and 24.1 for site 2 by first PCR, 23.2 and 25.3 after confirmation by second PCR); Bourbon virus was not detected. The estimated prevalence of HRTV in adult male A. americanum ticks was 9.46/1,000 ticks at site 1 and 7.60/1,000 ticks at site 2 (Table 2 ).

\section{Conclusions}

One year after 2 cases in humans were detected, HRTV was detected in A. americanum ticks collected from the suspected exposure locations in Illinois. Because of abundant suitable habitat and established A. americanum tick populations (10), it is notable but predictable that this pathogen emerged in southern Illinois. The density of and HRTV detection in A. americanum ticks at the northern edge of their distribution range in Kankakee County was unexpected. Our findings suggest that $A$. americanum

\begin{tabular}{|c|c|c|c|c|}
\hline Site, method, tick species & Stage & Sex & No. collected & Density/1,000 $\mathrm{m}^{2}$ \\
\hline Site $1^{*}$ & & & 659 & \\
\hline \multicolumn{5}{|l|}{ Dragging } \\
\hline \multirow[t]{3}{*}{ Amblyomma americanum } & Adult & $\mathrm{F}$ & 93 & 26 \\
\hline & Adult & M & 90 & 25 \\
\hline & Nymph & Not applicable & 338 & 93 \\
\hline \multirow[t]{2}{*}{ Dermacentor variabilis } & Adult & $\mathrm{F}$ & 15 & 4 \\
\hline & Adult & $M$ & 10 & 3 \\
\hline \multicolumn{5}{|l|}{ Carbon-dioxide trap } \\
\hline \multirow[t]{3}{*}{ A. americanum } & Adult & $\mathrm{F}$ & 18 & Not applicable \\
\hline & Adult & M & 17 & Not applicable \\
\hline & Nymph & Not applicable & 75 & Not applicable \\
\hline \multirow[t]{2}{*}{ D. variabilis } & Adult & $\mathrm{F}$ & 1 & Not applicable \\
\hline & Adult & $M$ & 1 & Not applicable \\
\hline Ixodes scapularis & Nymph & Not applicable & 1 & Not applicable \\
\hline \multicolumn{5}{|l|}{ Site $2 \dagger$} \\
\hline \multicolumn{5}{|l|}{ Dragging } \\
\hline \multirow[t]{3}{*}{ A. americanum } & Adult & $\mathrm{F}$ & 32 & 15 \\
\hline & Adult & M & 44 & 21 \\
\hline & Nymph & Not applicable & 159 & 76 \\
\hline \multirow{2}{*}{ D. variabilis } & Adult & $\mathrm{F}$ & 1 & 0.5 \\
\hline & Adult & M & 2 & 1 \\
\hline \multicolumn{5}{|l|}{ Carbon-dioxide trap } \\
\hline \multirow[t]{3}{*}{ A. americanum } & Adult & $\mathrm{F}$ & 118 & Not applicable \\
\hline & Adult & $M$ & 88 & Not applicable \\
\hline & Nymph & Not applicable & 48 & Not applicable \\
\hline \multirow[t]{2}{*}{ D. variabilis } & Adult & $\mathrm{F}$ & 3 & Not applicable \\
\hline & Adult & $M$ & 3 & Not applicable \\
\hline \multirow{2}{*}{\multicolumn{5}{|c|}{$\begin{array}{l}\text { Site } 3 \ddagger \\
\quad \text { Carbon-dioxide trap }\end{array}$}} \\
\hline & & & & \\
\hline \multirow[t]{2}{*}{ A. americanum } & Adult & $\mathrm{F}$ & 4 & Not applicable \\
\hline & Nymph & Not applicable & 4 & Not applicable \\
\hline D. variabilis & Adult & $\mathrm{F}$ & 1 & Not applicable \\
\hline
\end{tabular}


Table 2. Prevalence of Heartland virus in ticks, by location, species, and sex in 2 counties in Illinois, USA, 2019*

\begin{tabular}{|c|c|c|c|c|c|c|c|}
\hline Species & Stage & Sex & County & $\begin{array}{l}\text { No. ticks } \\
\text { collected }\end{array}$ & No. pools & $\begin{array}{l}\text { No. positive } \\
\text { pools }\end{array}$ & $\begin{array}{c}\text { Infection rate } / 1,00 \text { ticks, } \\
\text { MLE }(95 \% \mathrm{Cl})\end{array}$ \\
\hline Amblyomma americanum & Adult & $\mathrm{M}$ & Kankakee & 107 & 16 & 1 & $9.46(0.55-46.1)$ \\
\hline A. americanum & Adult & $\mathrm{F}$ & Kankakee & 111 & 12 & 0 & $0(0-29.5)$ \\
\hline A. americanum & Nymph & NA & Kankakee & 413 & 15 & 0 & $0(0-8.2)$ \\
\hline A. americanum & Adult & $M$ & Williamson & 132 & 15 & 1 & $7.6(0.44-36.9)$ \\
\hline A. americanum & Adult & $\mathrm{F}$ & Williamson & 154 & 17 & 0 & $0(0-22.16)$ \\
\hline A. americanum & Nymph & NA & Williamson & 211 & 8 & 0 & $0(0-14.5)$ \\
\hline Dermacentor variabilis & Adult & Both & Kankakee & $27(16 \mathrm{~F}, 11 \mathrm{M})$ & 4 & 0 & $0(0-92.8)$ \\
\hline D. variabilis & Adult & Both & Williamson & $10(5 \mathrm{~F}, 5 \mathrm{M})$ & 6 & 0 & $0(0-248.8)$ \\
\hline
\end{tabular}

ticks are established along their northern distribution range at high densities. Consequently, diseases associated with $A$. americanum ticks must be on the radar of physicians and public health officials throughout Illinois.

Detection of HRTV in adult $A$. americanum ticks suggests that infected ticks may have overwintered in the area and maintained HRTV infection transstadially. The presence of HRTV in adult male, but not female or nymph, ticks was also reported in a study in Kansas, where the infection rate varied from 3.29 to $8.62 / 1,000$ ticks (15), similar to our findings. Additional tick collection efforts and wildlife serosurveys will help assess whether transmission cycles are active in Illinois and enhance our knowledge of the transmission ecology of this rare pathogen.

\section{Acknowledgments}

We are grateful to the Heartland case-patients, who allowed us to conduct tick collections. We thank Bethany McGregor, who assisted with tick homogenization; and Kayla Valcheva, Ashley Ray, and Alan Hatia, who helped with tick dragging. We also thank Roxanne Connelly and anonymous reviewers for comments on this manuscript.

This work was supported through an agreement with the Illinois Department of Public Health. Points of view or opinions expressed in this document are those of the authors and do not necessarily represent the official position or policies of the Illinois Department of Public Health or the Centers for Disease Control and Prevention. The INHS Medical Entomology Lab is additionally supported through the State of Illinois Used Tire Management and Emergency Public Health Funds.

\section{About the Author}

Dr. Tuten is a vector ecologist at the Illinois Natural History Survey at the University of Illinois at UrbanaChampaign, in Champaign, Illinois. Her research interests are vector behavior, control, ecology, demography, pathogens, and population genetics. Dr. Burkhalter is a microbiologist in the Division of Vector-Borne Diseases, National Center for Emerging and Zoonotic Infectious Diseases, CDC, Fort Collins, CO. Her research interests include the development and optimization of methods to improve detection of arboviruses in environmental samples and providing support for $\mathrm{CDC}^{\prime}$ s public health partners.

\section{References}

1. Brault AC, Savage HM, Duggal NK, Eisen RJ, Staples JE. Heartland virus epidemiology, vector association, and disease potential. Viruses. 2018;10:498. https:// doi.org/ 10.3390/v10090498

2. Savage HM, Godsey MS, Lambert A, Panella NA, Burkhalter KL, Harmon JR, et al. First detection of Heartland virus (Bunyaviridae: Phlebovirus) from field collected arthropods. Am J Trop Med Hyg. 2013;89:445-52. https:/ / doi.org/10.4269/ajtmh.13-0209

3. Bosco-Lauth AM, Panella NA, Root JJ, Gidlewski T, Lash RR, Harmon JR, et al. Serological investigation of Heartland virus (Bunyaviridae: Phlebovirus) exposure in wild and domestic animals adjacent to human case sites in Missouri 2012-2013. Am J Trop Med Hyg. 2015;92:1163-7. https://doi.org/10.4269/ajtmh.14-0702

4. McMullan LK, Folk SM, Kelly AJ, MacNeil A, Goldsmith CS, Metcalfe MG, et al. A new phlebovirus associated with severe febrile illness in Missouri. N Engl J Med. 2012;367:83441. https://doi.org/10.1056/NEJMoa1203378

5. Godsey MS Jr, Savage HM, Burkhalter KL, Bosco-Lauth AM, Delorey MJ. Transmission of Heartland Virus (Bunyaviridae: Phlebovirus) by experimentally infected Amblyomma americanum (Acari: Ixodidae). J Med Entomol. 2016;53:122633. https://doi.org/10.1093/jme/tjw080

6. Savage HM, Godsey MS Jr, Panella NA, Burkhalter KL, Ashley DC, Lash RR, et al. Surveillance for Heartland virus (Bunyaviridae: Phlebovirus) in Missouri during 2013: first detection of virus in adults of Amblyomma americanum (Acari: Ixodidae). J Med Entomol. 2016;53:607-12. https://doi.org/10.1093/jme/tjw028

7. Riemersma KK, Komar N. Heartland virus neutralizing antibodies in vertebrate wildlife, United States, 2009-2014. Emerg Infect Dis. 2015;21:1830-3. https:/ / doi.org/10.3201/ eid2110.150380

8. Sonenshine DE. Range expansion of tick disease vectors in North America: implications for spread of tick-borne disease. Int J Environ Res Public Health. 2018;15:478. https:// doi.org/10.3390/ijerph15030478

9. Raghavan RK, Peterson AT, Cobos ME, Ganta R, Foley D. Current and future distribution of the lone star tick, Amblyomma americanum (L.) (Acari: Ixodidae) in North 
America. PLoS One. 2019;14:e0209082. https:/ / doi.org/ 10.1371/journal.pone.0209082

10. Springer YP, Jarnevich CS, Barnett DT, Monaghan AJ, Eisen RJ. Modeling the present and future geographic distribution of the lone star tick, Amblyomma americanum (Ixodida: Ixodidae), in the continental United States. Am J Trop Med Hyg. 2015;93:875-90. https:// doi.org/10.4269/ajtmh.15-0330

11. Keirans JE, Durden LA. Illustrated key to nymphs of the tick genus Amblyomma (Acari: Ixodidae) found in the United States. J Med Entomol. 1998;35:489-95. https:/ / doi.org/10.1093/ jmedent/35.4.489

12. Keirans JE, Litwak TR. Pictorial key to the adults of hard ticks, family Ixodidae (Ixodida: Ixodoidea), east of the Mississippi River. J Med Entomol. 1989;26:435-48. https://doi.org/10.1093/jmedent/26.5.435

13. Savage HM, Burkhalter KL, Godsey MS Jr, Panella NA, Ashley DC, Nicholson WL, et al. Bourbon virus in field- collected ticks, Missouri, USA. Emerg Infect Dis. 2017;23:2017-22. https://doi.org/10.3201/eid2312.170532

14. Biggerstaff BJ. PooledInfRate, version 4.0: a Microsoft ${ }^{\circledR}$ Office Excel@ add-in to compute prevalence estimates from pooled samples. Fort Collins (CO): Centers for Disease Control and Prevention; 2009.

15. Savage HM, Godsey MS Jr, Panella NA, Burkhalter KL, Manford J, Trevino-Garrison IC, et al. Surveillance for tick-borne viruses near the location of a fatal human case of bourbon virus (Family Orthomyxoviridae: Genus Thogotovirus) in eastern Kansas, 2015. J Med Entomol. 2018;55:701-5. https://doi.org/10.1093/jme/tjx251

Address for correspondence: Holly. C. Tuten, Biocontrol Laboratory, 1902 Griffith Dr, Champaign, IL 61820, USA; email: htuten@illinois.edu

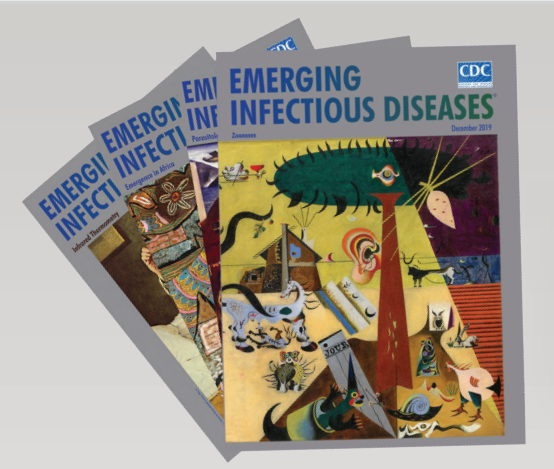

Seroprevalence and Risk Factors Possibly Associated with Emerging Zoonotic Vaccinia Virus in a Farming Community, Colombia

Patterns of Transmission and Sources of Infection in Outbreaks of Human Toxoplasmosis

Global Epidemiology of Buruli Ulcer, 2010-2017, and Analysis of 2014 WHO Programmatic Targets

Cost-effectiveness of Prophylactic Zika Virus Vaccine in the Americas

Human Infection with Orf Virus and Description of Its Whole Genome, France, 2017

High Prevalence of Macrolide-Resistant Bordetella pertussis and ptxP1 Genotype, Mainland China, 2014-2016

Avian Influenza A Viruses among Occupationally Exposed Populations, China, 2014-2016

Genomic Analysis of Fluoroquinolone- and Tetracycline-Resistant Campylobacter jejuni Sequence Type 6964 in Humans and Poultry, New Zealand, 2014-2016

Streptococcus suis-Associated Meningitis, Bali, Indonesia, 2014-2017

Epidemiologic, Entomologic, and Virologic Factors of the 2014-15 Ross River Virus Outbreak, Queensland, Australia

Multicountry Analysis of Spectrum of Clinical Manifestations in Children $<5$ Years of Age Hospitalized with Diarrhea

Sheep as Host Species for Zoonotic Babesia venatorum, United Kingdom
Half-Life of African Swine Fever Virus in Shipped Feed

Zika Virus IgM 25 Months after Symptom Onset, Miami-Dade County, Florida, USA

Divergent Barmah Forest Virus from Papua New Guinea

Animal Exposure and Human Plague, United States, 1970-2017

Sentinel Listeriosis Surveillance in Selected Hospitals, China, 2013-2017

Economic Impact of Confiscation of Cattle Viscera Infected with Cystic Echinococcosis, Huancayo Province, Peru

Predicting Dengue Outbreaks in Cambodia

Cat-to-Human Transmission of Mycobacterium bovis, United Kingdom Evolution of Highly Pathogenic Avian Influenza A(H5N1) Virus in Poultry, Togo, 2018

West Nile Virus in Wildlife and Nonequine Domestic Animals, South Africa, 2010-2018

Highly Pathogenic Avian Influenza A(H5N8) Virus in Gray Seals, Baltic Sea Bagaza Virus in Himalayan Monal Pheasants, South Africa, 2016-2017 Influenza A(H1N1)pdm09 Virus Infection in a Captive Giant Panda, Hong Kong

Middle East Respiratory Syndrome Coronavirus Seropositivity in Camel Handlers and their Families, Pakistan

To revisit the December 2019 issue, go to:

https://wwwnc.cdc.gov/eid/articles/issue/25/12/table-of-contents 